\title{
Aplicação de redes neurais artificiais na cultura do mogno (Khaya spp. e Swietenia spp.)
}

\author{
Marcos Cardoso Silva ${ }^{\mathrm{a}^{*}}{ }^{\circ}$, Francisca Cássia Silva da Silva ${ }^{\mathfrak{a}}{ }^{\oplus}$, Igor Viana Souza ${ }^{\mathfrak{a}}{ }^{\oplus}$,

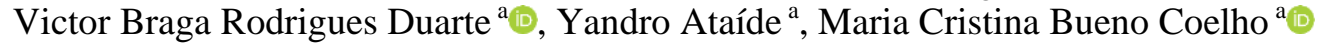 \\ ${ }^{a}$ Universidade Federal do Tocantins (UFT), Brasil \\ *Autor correspondente (markuz.cardoso12@gmail.com)
}

\section{N F O}

\section{Keyworks}

artificial intelligence

biometrics

measurement

\section{Palavras-chaves}

inteligência artificial biometria

mensuração

\begin{abstract}
A B S T R A C T
Application of artificial neural networks in the mahogany culture (Khaya spp. e Swietenia spp.)

Due to their high commercial value and acceptance in the international market, mahogany species have been exploited indiscriminately, even in protected areas, resulting in threat of extinction. Mahogany species are desirable both in terms of color and grain patterns and in their properties. physical and mechanical. Both species have similar characteristics and are considered resistant to the attack of fungi and termites. Mahogany (Khaya spp. and Swietenia spp.) Has great productive potential in Brazil, being a good alternative to the most expressive crops in the country, for example. Since they are noble woods, and like Mahogany, Artificial Neural Networks (RNAs) are also good alternatives to estimate different dendrometric variables in different cultures, and studies show that this technique has been producing excellent adjustments, especially when compared to regression models. Traditional Thus, this review aimed to provide information on the different applications of RNAs in mahogany crops in Brazil.
\end{abstract}

\section{R E S U M O}

Devido ao seu alto valor comercial e aceitação no mercado internacional, as espécies de mogno foram exploradas indiscriminadamente, mesmo em áreas protegidas, resultando em ameaça de extinção. As espécies de mogno são desejáveis tanto em termos de cores e padrões de grãos quanto em suas propriedades físicas e mecânicas. Ambas as espécies têm características semelhantes e são consideradas resistentes ao ataque de fungos e cupins. A cultura do Mogno (Khaya spp. e Swietenia spp.) apresenta grande potencial produtivo no Brasil, sendo uma boa alternativa às culturas de maior expressão no país, por se tratar de madeiras nobres, e assim como o Mogno, as Redes Neurais Artificiais (RNAs) também são boas alternativas para estimar diferentes variáveis dendrométricas em diferentes culturas, e estudos comprovam que essa técnica vem produzindo ótimos ajustes, principalmente quando comparados aos modelos de regressão tradicionais. Sendo assim a presente revisão teve como objetivo trazer informações das diferentes aplicações das RNAs nas culturas do Mogno no Brasil. 


\section{INTRODUÇÃO}

Os recursos de madeira nativa no Brasil têm sido explorados de maneira insustentável por anos, em grande parte devido à alta demanda por recursos florestais, resultando em vastas áreas de desmatamento. O reflorestamento começou com a plantação de Eucalyptus spp. principalmente para fornecer madeira para a construção de ferrovias. Nos anos 60, os incentivos fiscais levaram à introdução de Pinus spp. na região sul do Brasil como um material alternativo adicional para acompanhar a demanda por produtos de madeira. Segundo a Associação Brasileira de Florestas Plantadas (ABRAF, 2013).

Atualmente, as plantações de Eucalyptus e Pinus representam as duas principais espécies de madeira cultivadas no Brasil. No entanto, outras espécies de madeira também foram cultivadas em plantações, incluindo Acacia mearnsii, Hevea spp., Tectona grandis, Schizolobium amazonicum Ducke e Araucaria angustifolia e as espécies do gênero Khaya.

Meliaceae de alto valor para madeira em florestas tropicais em todo o mundo compartilham características comerciais e ecológicas distintas: madeira cujas excelentes propriedades de trabalho são combinadas com uma beleza excepcional; as faixas naturais coincidem amplamente com as florestas sazonais sofrendo uma rápida conversão antropogênica para outros usos da terra; populações de baixa densidade, tipicamente menores que 1 árvore comercial ha ${ }^{-1}$; e histórias de vida geralmente caracterizadas como secundárias tardias não pioneiras, com taxas de crescimento rápidas, sementes dispersas pelo vento ou pela água e regeneração avançada de mudas de baixa densidade no sub-bosque, exigindo distúrbios no dossel para o crescimento ideal das mudas (Grogan et al., 2008).

\section{REVISÃO BIBLIOGRÁFICA}

Atualmente, há um interesse crescente no mogno africano cultivado em plantações (Khaya spp.) como substituto da alta demanda por mogno brasileiro nativo (Swietenia macrophylla King). Esse interesse comercial pelo mogno africano decorreu da redução do mogno brasileiro nativo nas regiões onde ocorre. Em 1976, cinco mudas de mogno africano (Khaya ivorensis A. Chev.) Foram plantadas na Empresa Brasileira de Pesquisa Agropecuária (EMBRAPA - Amazônia Oriental). Esses espécimes foram eventualmente utilizados para iniciar plantações em outras regiões do país.

Como em quase todas as espécies de madeira tropical, pouco se sabe sobre os padrões de distribuição e densidade regional e local, caracterizando Meliaceae de alto valor (Grogan e Barreto, 2005). Isso significa que existe pouca base empírica para avaliar os impactos da exploração madeireira em populações comerciais, ou para projetar taxas de recuperação e avaliar a sustentabilidade das práticas atuais de colheita. Esse problema refere-se até ao Mogno Brasileiro (Swietenia macrophylla), o mais amplamente estudado e explorado das Meliaceae tropicais, cuja lista na Convenção sobre Comércio Internacional de Espécies Ameaçadas de Fauna e Flora (CITES), apêndice II em 2002, exige que os organismos internacionais, o comércio envolve apenas volumes colhidos legalmente, considerados não prejudiciais ao seu papel no ecossistema (Blundell, 2004).

Segundo o estudo de Casaroli et al. (2018), o estado do Tocantins é um dos estados brasileiros considerados aptos para o cultivo do Mogno Africano devido suas condições edafoclimáticas que são bastante favoráveis para a espécie.

Nas práticas de manejo e acompanhamento do desenvolvimento de determinada cultura, é usual a presença de modelos estatísticos que visem fornecer valores índices a respeito das taxas de incremento médio da espécie de interesse, seja esse incremento em altura ou volume. A relação hipsométrica em geral pode ser compreendida como uma regressão da altura sobre o diâmetro em uma população com base em um período específico, demais características silviculturais do povoamento e do sítio onde está instalado (Caldeira, 2017). A qualidade dos modelos é julgada com base nos critérios estatísticos adotados para cada situação e a seleção obedece basicamente a premissa de que ambas as variáveis diâmetro e altura obtenham forte correlação entre si.

O desenvolvimento de estudos voltados para a otimização da produção visando atender as exigências e necessidades do mercado consumidor é de extrema importância. Para isso, é necessário quantificar e prognosticar os estoques da floresta, a fim de definir a utilização dos bens advindos da mesma e obter informações para possíveis tomadas de decisão. Dados de diâmetro, altura, área basal e volume das árvores são importantes nas estimativas dos estoques, presente e futuro da produção de madeira de uma floresta (Jesus et al. 2017).

Dentre as variáveis dendrométricas estudadas na floresta, tanto nativa quanto plantada, o volume se constitui em uma das informações com maior importância para o conhecimento do possível potencial florestal de uma região, sendo que o volume individual é o primeiro passo para avaliação da produtividade de povoamentos florestais (Morandi et 
al, 2017). A cubagem de árvores, além de ser essencial para se caracterizar o comportamento do diâmetro ao longo do tronco, também é eficaz para determinar o volume das árvores abatidas, que pode ser obtido pelo emprego de diferentes fórmulas, das quais se destacam as fórmulas de Smalian, Huber, Newton e Hohenadl.

Várias técnicas alternativas à regressão tradicional vêm sendo aplicadas na área florestal (Gorgens et al., 2009; Leite et al., 2010). No decorrer dos anos, com o objetivo de tornar as estimativas mais precisas e facilitar o trabalho do engenheiro florestal responsável pelos inventários florestais e sortimento de madeira, que é o objetivo principal quando se trata de florestas de produção, tendo a aplicação das redes neurais artificiais (RNA) apresentado bastante sucesso (Astro et al., 2013; Binoti et al., 2015; Reis et al., 2016).

$\mathrm{O}$ uso das redes neurais artificiais vem se tornando uma alternativa bastante eficiente, elas simulam o funcionamento do cérebro humano, e quando treinadas podem estimar as variáveis desejáveis com maior precisão que os modelos tradicionais normalmente utilizados (Garber e Maguire, 2003; Binoti et al., 2013; Binoti et al., 2012a; Binoti et al., 2012b; Leite et al., 2010; Silva et al.,2009).

Os parâmetros do modelo podem ser estimados por meio de regressão e inteligência artificial, principalmente Redes Neurais Artificiais - RNA. As RNAs podem ser mais precisas do que a regressão devido a relações complexas entre fatores biologicamente dependentes ou não biológicos, por isso são eficientes para estimar os diferentes parâmetros dendrométricos, como altura e volume (Binoti et al, 2015).

Sendo assim, o objetivo desse artigo de revisão foi comparar as diferentes aplicações das Redes Neurais Artificiais na estimativa de diferentes variáveis dendrométricas na cultura do Mogno.

\section{Swietenia macrophylla}

O Mogno (Swietenia macrophylla) é uma das espécies de madeira mais valorizadas do mundo. Por muitas décadas, alguns países e / ou alguns organismos privados investiram em plantações para garantir uma produção sustentada de madeira de alto valor (Mead e Odoom, 2001; Lugo e Alayón, 2003). Tais casos existem na Ásia (Indonésia, Filipinas, Sri Lanka e Fiji), onde as espécies encontram boas condições de crescimento (Hammond et al., 2002) e, em menor grau, em alguns países da América Central (Costa Rica) e América do Sul (Brasil, Peru, Bolívia). No mercado internacional de 2011, o preço médio em metros cúbicos de madeira serrada de mogno do Brasil e da Guatemala foi de US\$ 1195 e US\$ 1884, respectivamente (ITTO, 2014).
O mogno cresce naturalmente em Belize, Bolívia, Brasil, Colômbia, Costa Rica, Equador, El Salvador, Guatemala, Honduras, México, Nicarágua, Panamá, Peru e Venezuela. No entanto, está quase extinto no Equador, Colômbia, Panamá e Costa Rica; quase extinção comercial na Bolívia; declínio no México, Belize e Brasil; e em severo declínio na Guatemala, Peru, Nicarágua e Honduras (Lugo \& Alayón, 2013; Grogan et al., 2010).

As maiores plantações de Swietenia macrophylla foram registradas no sul e sudeste da Ásia e nas regiões do Pacífico. O mogno tornou-se uma espécie de árvore promissora para plantações industriais, bem como para reflorestamento e arborização. O mogno é adequado para plantações de produção de madeira em larga escala devido à sua excelente qualidade da madeira. Geralmente, a madeira pode ser usada para materiais de construção, compensado (folheado), móveis de alta qualidade e marcenaria. Também é adequado para painéis, molduras, pisos, carrocerias de automóveis, guarnições internas de barcos, gabinetes de rádio e fonógrafo, carrocerias de instrumentos musicais, molduras e outros ornamentos (Krisnawati et al., 2011). No entanto, algumas propriedades da madeira, como a densidade do xilema, retração tangencial e radial, módulo de elasticidade e módulo de ruptura do mogno diferem entre floresta natural e floresta plantada (Langbour et al., 2011); esses achados podem influenciar a utilização específica da madeira do mogno plantado.

\section{GÊNERO KHAYA}

A Associação Brasileira de Produtores de Mogno Africano (ABPMA) estima que existam aproximadamente 10.000 hectares cultivados de Mogno Africano em todo o Brasil, isso se juntarmos as diferentes espécies (Khaya ivorensis, Khaya senegalensis, Khaya anthotheca e Khaya grandiflora), e a cada ano a espécie tem ganhado mais espaço no cenário silvicultural brasileiro (ABPMA, 2015).

A implantação da espécie foi iniciada no Pará em 1976, na Sede da Embrapa Amazônia Ocidental, com estabelecimento de 5 matrizes, e os povoamentos vem desde então sendo alvo de intensa pesquisa visando a domesticação e elevação da produtividade, tendo em vista que a mesma não sofre danos graves pela Broca das Meliaceaes (Hypsipyla grandella Zeller), como ocorre com o mogno brasileiro Swietenia macrophylla (Pinheiro et al, 2011).

As espécies do gênero Khaya, comumente conhecido como mogno da zona seca ou mogno africano, é uma árvore de madeira dura pertence à família Meliaceae. Dá excelente mobiliário de ma- 
deira com uma aparência atraente. Também é amplamente utilizado na construção de edifícios para membros estruturais e para portas, esquadrias e telhas (Ribeiro et al., 2017).

A cor do cerne de Khaya ivorensis varia de marrom amarelado a marrom avermelhado e possui alburno marrom amarelado (Wiemann, 2010). O cerne de Khaya senegalensis varia de cor rosada a avermelhada, com alburno amarelado (Zbonak et al., 2010). Além das propriedades físicas favoráveis do mogno africano, Khaya spp. também demonstrou ter algumas características naturais de durabilidade, como resistência à larva, Hypsiphyla grandella, uma praga comum em muitas plantações de mogno no Brasil. Essas características sugerem que os materiais de madeira dessas espécies têm o potencial de atender às necessidades do mercado de madeira maciça, bem como os padrões de qualidade da indústria da madeira (Pinheiro et al., 2012).

\section{ESTRUTURA DAS REDES NEURAIS ARTIFICIAIS (RNAs)}

As RNAs são ferramentas virtuais baseadas nos neurônios naturais, que possuem capacidade de treinamento e aprendizado similares ao cérebro humano, e são formadas basicamente por três camadas, camada de entrada, camada intermediária ou camada oculta, e camada de saída. A camada de entrada tem como função receber as informações que já foram obtidas anteriormente, e essas informações serão repassadas para as demais camadas. A camada intermediária ou camada oculta tem a função de absorver as informações que foram inseridas na camada de entrada e auxiliar na resolução do problema que será solucionado, e a camada de saída, que é onde a solução do problema será gerado.

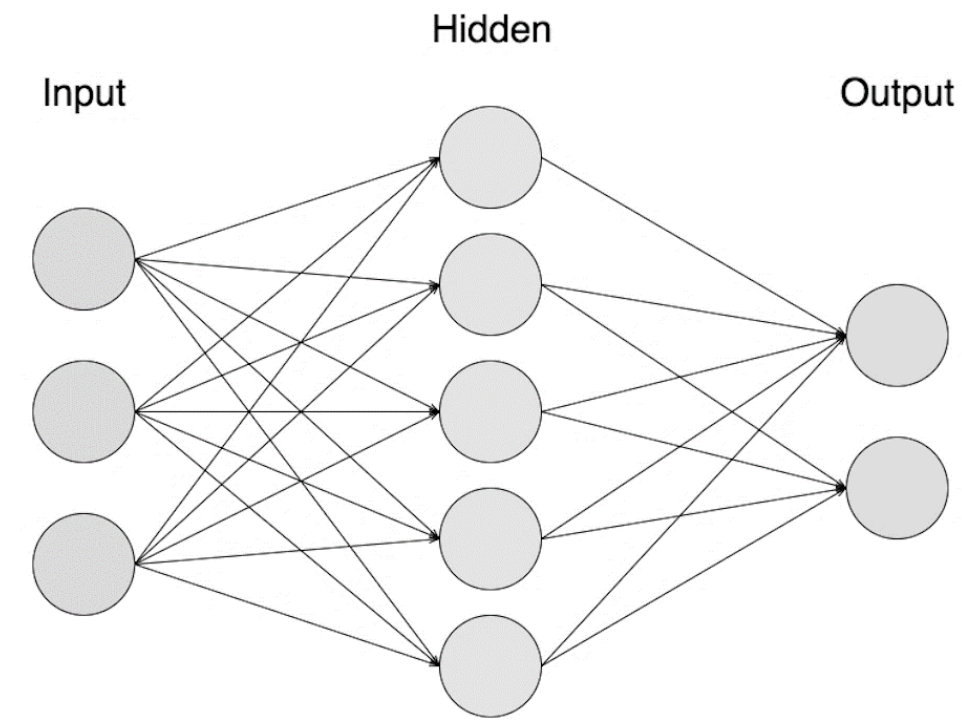

Figura 1 - Estrutura de uma Rede neural artificial (Fonte: Autor).

Exemplificando para a área florestal, suponhamos que desejamos treinar uma rede neural para estimar o volume em uma floresta. Teremos 2 camadas de entrada, que serão os valores do diâmetro à altura do peito (DAP) e altura comercial (Hc) obtidos na cubagem rigorosa, e na camada de saída teremos o volume rigoroso das árvores cubadas da mesma floresta. Com esses dados será feito o treinamento de diferentes redes, onde elas irão encontrar um padrão de similaridade entre os dados de entrada e saída, e assim gerar valores estimados com a máxima precisão possível. Futuramente, no próximo inventário florestal dessa área hipotética, serão necessários apenas os dados de DAP e Hc, e a rede neural irá estimar o volume das árvores.

Muitos estudos foram realizados em todo o mundo (Newnham, 1964; Soares e Tomé, 1997; Crescente-Campo et al., 2010), na tentativa de melhorar os modelos de crescimento nível de árvore individual e os submodelos relevantes. Métodos para estimar parâmetros, bem como diferentes variáveis explicativas foram avaliados na tentativa de produzir informações precisas e imparciais estimativas de crescimento de diâmetro e altura e também da mortalidade de árvores.

Além do método de ajuste tradicional para os modelos no nível de uma árvore individual, com base na regressão linear e não linear, alternativamente, a inteligência artificial pode ser usada através das Redes Neurais Artificiais (RNAs) (Diamantopoulou, 2005). Uma RNA cria um conjunto 
de unidades de processamento paralelo, caracterizadas por neurônios artificiais que são interconectados através de um grande número de interconexões (Silva et al., 2010).

Alguns estudos mostraram a aplicação bem-sucedida de RNAs na modelagem de árvores individuais, como, por exemplo, para estimar o crescimento e a mortalidade em florestas com idades desiguais (Ashraf et al., 2015, Castro et al., 2015, Richards et al. al., 2008) e em florestas com idades iguais (Castro et al., 2013a, Castro et al., 2013b).

Normalmente, estimativas de parâmetros de equação para os modelos são derivados de regressões lineares e não lineares (Campos e Leite, 2009; Miehle et al., 2009). No entanto, outras técnicas de estimativa que incluem redes neurais têm sido usadas com sucesso na mensuração de florestas (Merkl e Hasenauer, 1998; Silva et al., 2009) fornecendo estimativas tão precisas quanto aquelas derivadas por modelos de regressão (Leite et al., 2011).

\section{APLICAÇÕES DAS RNAS}

Santos Neto (2018), testou o uso das RNAs para estimar volume (dado de saída) de madeira em um plantio comercial de Khaya ivorensis com idades entre 30 e 47 meses e espaçamento de $3 \times 4$ metros, no município de Pirapora, estado de Minas Gerais. Foram treinadas 30 redes para cada 18 algoritmos diferentes, totalizando 540 redes no total, utilizou $60 \%$ dos dados para treinamento e $40 \%$ para validação e teve como dados de entrada as variáveis altura total, e diâmetro à altura do peito. Em seus resultados, obteve uma correlação variando entre 0,9807 e 0,9932, e Raiz Quadrada média do Erro (RQME) em metros cúbicos, variando entre 0,0129 e 0,0380 .

Paula Filho e Tusset (2012) testaram RNA's na identificação da madeira de 14 espécies nativas, entre elas o Mogno (Swietenia macrophyla), através de uma análise de cor da madeira. Das 31.968 imagens do seu banco de dados, 20.971 foram classificadas corretamente, com uma taxa de acerto de $65,60 \%$.

Poucos são os estudos publicados voltados ao uso das RNA's nas culturas do Mogno, mas é possível encontrar resultados da aplicabilidade das RNA's em diferentes culturas nativas e exóticas.

Almeida (2015) ao aplicar as RNAs para estimativa de altura total e volume em povoamentos de Araucaria angustifólia, encontrou uma correlação de 0,863 e RQME de 13,94 para a variável altura total. Já para a variável volume encontrou uma correlação de variando entre 0,997 e 0,998 e RQME de 1,09 .

Lafetá et al. (2018) avaliou a eficiência das
RNAs para estimar a eficiência do uso de nutrientes no tronco de indivíduos de Eucalyptus em um plantio de híbridos de híbrido de Eucalyptus grandis W. Hill ex Maiden x Eucalyptus camaldulensis Dehnh no município de Itamarandiba-MG com diferentes espaçamentos, onde conseguiram um valor de RQME em torno de $25 \%$.

Silva et al. (2019) comparou modelos de regressão tradicionais e RNAs para estimar volume de madeira em um plano de manejo florestal no município de Portel-PA, região amazônica do Brasil onde ocorre naturalmente a presença da espécie Swietenia macrophylla, onde conseguiu um Erro Médio Relativo de 0,55\%, Erro Padrão da estimativa igual a 0,2553 e Coeficiente de Determinação igual a 0,9985, sendo estatisticamente semelhante ao modelo de Spurr, que foi o melhor avaliado entre os demais testados.

\section{CONSIDERAÇÕES FINAIS}

Ainda existem poucos estudos publicados utilizando a aplicação das RNAs em culturas de Mogno, mas os estudos encontrados mostram que o uso de RNAs é satisfatório e apresentam bastante potencial tanto em culturas de Mogno (Khaya spp e Swietenia spp.), quanto em outras culturas nativas ou exóticas no Brasil.

\section{REFERÊNCIAS BIBLIOGRÁFICAS}

Almeida TG de. Comparação entre redes neurais artificiais e modelos tradicionais de regressão para estimar altura e volume em povoamentos de Araucaria angustifolia (Bertol.) O. Kuntze. 2015. Trabalho de conclusão de curso (Bacharel em Engenharia Florestal) - Universidade Federal do Paraná, Curitiba, 2015.

Associação Brasileira dos Produtores de Mogno Africano, Apresentação. ABPMA, 2015. Disponível em: http://abpma.org.br/apresentacao/.

Ashraf M., Irfan et al. A novel modelling approach for predicting forest growth and yield under climate change. PloS one, v.10, n.7, 2015.

Binoti DHB et al. Redução dos custos em inventário de povoamentos equiâneos utilizando redes neurais artificiais. Agrária, v.8, p.125-129, 2012a

Binoti DHB et al. Modelagem da distribuição diamétrica em povoamentos de eucalipto submetidos a desbaste utilizando autômatos celulares. Revista Árvore, v.36, n.5, p.931-939, $2012 b$.

Binoti MLMS et al. Prognose em nível de povoamento de clones de eucalipto empregando redes neurais artificiais. Cerne, Lavras, v.21, n.1, p.97-105, 2015.

Blundell AG. A review of the CITES listing of big-leaf mahogany. Oryx, v.38, n.1, p.84-90, 2004. 
Caldeira, MVW et al. Relação hipsométrica para Araucaria angustifolia (Bert.) O. Ktze na região oeste do estado do Paraná. Revista Acadêmica: Ciência Animal, v.1, n.2, p.79-88, 2017.

Campos JCC, LEITE HG. Mensuração florestal: perguntas e respostas, Universidade Federal de Viçosa, Viçosa, Brasil, 2009.

Castro RVO et al. Crescimento e produção de plantios comercias de eucalipto estimados por duas categorias de modelo. Pesq. Agropec. Bras., Brasília, v.48, n.3, p.287-295, 2013.

Casaroli D. et al. Aptidão edafoclimática para o mogno africano no Brasil. Ciênc. Florestal., Santa Maria, v.28, n.1, p.357-368, 2018 .

Garber SM, Maguire DA. Modeling stem taper of three central oregon species using nonlinear mixed effects models and autoregressive error structures. Forest Ecology and Management, v.179, n.1, p.507-522, 2003.

Castro RVO et al. Artificial neural networks effectiveness to estimate mortality in a Semi-deciduous Seasonal Forest. Australian Journal of Basic and Applied Sciences, v.9, n.5, p.435-444, 2015

Castro RVO et al. Individual growth model for eucalyptus stands in Brazil using artificial neural network. ISRN Forestry, v. 2013. 2013.

Castro, Renato Vinícius Oliveira et al. Crescimento e produção de plantios comerciais de eucalipto estimados por duas categorias de modelos. Pesquisa Agropecuária Brasileira, v. 48 , n. 3 , p. $287-295,2013$.

Crescente-Campo F, Soares P, Tomé M, Diéguez-Aranda U. Modeling noncatastrophic individual tree mortality for Pinus radiate plantations in northwestern Spain. Forest Ecology and Management, v.257, n.6, p.1542-1550, 2010.

Diamantopoulou MJ. Artificial neural networks as an alternative tool in pine bark volume estimation. Computers and Electronics in Agriculture, v.48, n.3, p.235-244, 2005.

Goergens EB et al. Estimação do volume de árvores utilizando redes neurais artificiais. Revista Árvore, v.33, n.6, p.1141-1147, 2009.

Grogan J et al. What loggers leave behind: impacts on bigleaf mahogany (Swietenia macrophylla) commercial populations and potential for post-logging recovery in the Brazilian Amazon. Forest Ecology and Management, v.255, n.2, p.269-281, 2008.

Grogan J, Barreto P. Big-leaf mahogany on CITES Appendix II: big challenge, big opportunity. Conservation Biology, v.19, n.3, p.973-976, 2005.

Grogan J et al. Over-harvesting driven by consumer demand leads to population decline: Big-leaf mahogany in South America. Conservation Letters, v.3, n.1, p.12-20, 2010.

Hammond D. et al. Hardwood programmes in Fiji, Solomon Islands, and Papua New Guinea. 2002.

Jesus CM et al. (2017), Funções de densidade de probabilidade para estimativa das distribuições de variáveis dendrométricas em um povoamento clonal de eucalipto. Revista Espacios. v.38, n.16. 30p.
Krisnawati H, Kallio MH, Kanninen M. Swietenia macrophylla King: Ecology, silviculture and productivity. CIFOR, 2011.

Lafetá BO et al. Eficiência de utilização de macronutrientes em eucalipto por método não destrutivo estimados por redes neurais artificiais. Ciência Florestal, v.28, n.2, p.613623, jun. 2018.

Langbour P et al. Comparison of wood properties of planted big-leaf mahogany (Swietenia macrophylla) in martinique island with naturally grown mahogany from Brazil, Mexico and Peru. Journal of Tropical Forest Science, p.252259, 2011.

Leite HG et al. Estimation of inside-bark diameter and heartwood diameter for Tectona grandis Linn. trees using artificial neural networks. European Journal of Forest Research, v.130, n.2, p.263-269, 2010.

Leite HG, da Silva MLM, Binoti DHB, Fardin L, Takizawa FH. Estimation of inside-bark diameter and heartwood diameter for Tectona grandis Linn. trees using artificial neural networks. European Journal of Forest Research, v.130, n.2, p.263-269, 2011

Lugo AE, Alayón M. Big-leaf mahogany: Genetics, ecology and management. Springer Science \& Business Media, 2003.

Mead DJ, Odoom FK. Promotion of valuable hardwood plantations in the tropics. A global overview. Forest Plantations Thematic Papers. Working Paper (FAO), 2001.

Merkl D, Hasenauer H. Using neural networks to predict individual tree mortality. em Proceedings of the Int'l Conference on Engineering Applications of Neural Networks, p.10-12, Gibraltar, Reino Unido, 1998.

Miehle P, Battaglia M, Sands PJ et al. A comparison of four process-based models and a statistical regression model to predict growth of Eucalyptus globulus plantations. Ecological Modelling, v.220, n.5, p.734-746, 2009.

Morandi PS et al. Influência da disponibilidade de luz na qualidade de mudas e nutrição mineral de Calophyllum brasiliense Cambess. (Calophyllaceae). Revista Árvore, Viçosa, v.41, n.2, p.1-10, abr. 2017.

Newnham RM. The development of a standmodel for Douglasfir [Ph.D. thesis], University of British Columbia, Canada, 1964.

Paula Filho P, Tusset A. Análise de cor para o reconhecimento de espécies florestais. Ágora : revista de divulgação científica, v.16, n.2esp., p.330-341, 11 abr. 2012.

Pinheiro AL. et al. Ecologia, silvicultura e tecnologia de utilização dos mognos africanos (Khaya spp.). Viçosa: 2011, p.102. SEPLAN. Atlas do Tocantins: subsídios ao planejamento da gestão territorial. 6. ed. Palmas: Secretaria do Planejamento e da Modernização da Gestão Pública, 80 p. 2012.

Reais LP et al. Prognosis on the diameter of individual trees on the eastern region of the amazon using artificial neural networks. Forest Ecology and Management, Amsterdam, v.382, p.161-167, 2016 
Richards M, McDonald AJS, Aitkenhead MJ. Optimisation of competition indices using simulated annealing and artificial neural networks. Ecological Modelling, v.214, n.2-4, p.375-384, 2008

Ribeiro A et al. O cultivo do mogno africano (Khaya spp.) e o crescimento da atividade no Brasil. Floresta Ambiente. Seropédica, v.24, e00076814, 2017.

Santos Neto JC. Redes neurais artificiais na estimação de volume de Mogno Aricano (Khaya ivorensis). 2018. Trabalho de conclusão de curso (Bacharel em Engenharia Florestal) - Universidade Federal do Recôncavo Bahiano, Cruz das Almas, 2018.

Silva IN da, Spatti DH, Flauzino RA. Redes neurais artificiais para engenharia e ciências aplicadas. São Paulo: Artliber, v.23, n.5, p.33-111, 2010.

Silva MLM, Binoti DHB, Gleriani JM, Leite HG. Ajuste do modelo de Schumacher e Hall e aplicações de redes neurais artificiais para estimar volumes de árvores de eucalipto. Árvore, v.33, n.6, p.1133-1139, 2009.

Silva MVC, RamosYA, Limeira MMC, Coelho, MCB, Santos AF, Giongo M, Erpen ML. Uso de redes neurais artificiais e modelos de regressão para estimar volume de espécies nativas em Portel, Pará - Brasil. Revista Forestal Mesoamericana Kurú, v.17, n.40, 20 dez. 2019.

Wiemann MC. Characteristics and availability of commercially important woods. Wood handbook: wood as an engineering material: chapter 2. Centennial ed. General technical report FPL; GTR-190. Madison, WI: US Dept. of Agriculture, Forest Service, Forest Products Laboratory, 2010: v.190, p.2.1-2.45, 2010.

Zbonak A et al. Wood properties and processing outcomes for plantation grown African mahogany (Khaya senegalensis) trees from Clare, Queensland (18 and 20 year-old trees) and Katherine, Northern Territory (14 year-old trees). 2010. 